\title{
A child with neonatal onset multi-systemic inflammatory disease (NOMID)
}

\author{
*Daham de Silva ${ }^{1}$, Kavinda Chandimal Dayasiri ${ }^{2}$, Michelle de Silva ${ }^{2}$, Chamidri Naotunna ${ }^{2}$, Harendra de \\ Silva ${ }^{1}$
}

Sri Lanka Journal of Child Health, 2018; 47(2): 169-171

DOI: http://dx.doi.org/10.4038/sljch.v47i2.8486

(Key words: NOMID syndrome, neonatal onset multi-systemic inflammatory disease)

\section{Introduction}

Neonatal onset multi-systemic inflammatory disease (NOMID) is also known as chronic, infantile, neurological, cutaneous, and articular (CINCA) syndrome and only around 100 cases have been identified worldwide ${ }^{1}$. No cases have been reported in Sri Lanka ${ }^{1}$. In this report, the authors present a nine years old child with NOMID syndrome.

\section{Case report}

A nine year old boy, second live born child to healthy, non-consanguineous parents with a healthy sibling, presented for further evaluation of short stature, global developmental delay and anaemia. His antenatal period was uneventful. He was born at term by elective caesarean section, weighing $2.5 \mathrm{~kg}$. He had recurrent urticaria from 4 months of age up to 9 years. Recurrent febrile episodes were present up to 2 years since infancy. He was noted to have poor head control until 7 months of age. During subsequent follow up, he had global developmental delay which was accompanied by intellectual impairment.

Anthropometry revealed macrocephaly $(56 \mathrm{~cm}$, $>97^{\text {th }}$ centile) and confirmed short stature (height 93 $\mathrm{cm},<3 \mathrm{SD}$ and below mid-parental height range). Further clinical examination found marked pallor, clubbing, cervical, posterior auricular and inguinal lymphadenopathy, urticarial rash and facial dysmorphism. He had a $2 \mathrm{~cm}$ hepatomegaly. Vision assessment revealed papilloedema and optic atrophy.

\section{${ }^{1}$ Faculty of Medicine, University of Colombo, Sri Lanka, ${ }^{2}$ Lady Ridgeway for Hospital for Children, Colombo, Sri Lanka,}

*Correspondence: haresha_d@yahoo.com

(Received on 10 November 2016: Accepted after revision on 23 December 2016)

The authors declare that there are no conflicts of interest

Personal funding was used for the project.

Open Access Article published under the Creative

Commons Attribution CC-BY (c) (i)
Full blood count revealed microcytic, hypochromic anaemia (Haemoglobin $4.5 \mathrm{~g} / \mathrm{dl}$, mean corpuscular volume 56fl, mean corpuscular haemoglobin $23 \mathrm{pg}$, mean corpuscular haemoglobin concentration $25 \%$ ), leucocytosis (white cell count $37,000 \times 10^{3} / \mu \mathrm{L}$ ), neutrophilia $\left(28,000 \times 10^{3} / \mu \mathrm{L}\right)$, and eosinophilia $\left(2600 \times 10^{3} / \mu \mathrm{L}\right)$. Blood picture showed evidence of spherocytic haemolytic anaemia, predominantly microcytic hypochromic red cells and relative eosinophilia. TORCH screening, osmotic fragility test and cryohaemolysis test were negative. Inflammatory markers were elevated (ESR $80 \mathrm{~mm}$ first hour, CRP $87 \mathrm{mg} / \mathrm{L}$ ). Serum ferritin was low $(17 \mathrm{ng} / \mathrm{L})$. Renal and liver profiles were normal.

Abdominal ultrasound revealed hepatomegaly and para-aortic lymphadenopathy. Both kidneys did not show abnormal echogenicity suggestive of amyloid deposition. Bone age was delayed (4 years) at chronological age of 9 years. Electromyogram and nerve conduction studies did not show myopathy or neuropathy. Roentgenograms of both knee joints showed early arthropathy of NOMID syndrome including bony erosions and osteoporosis (Figure 1).

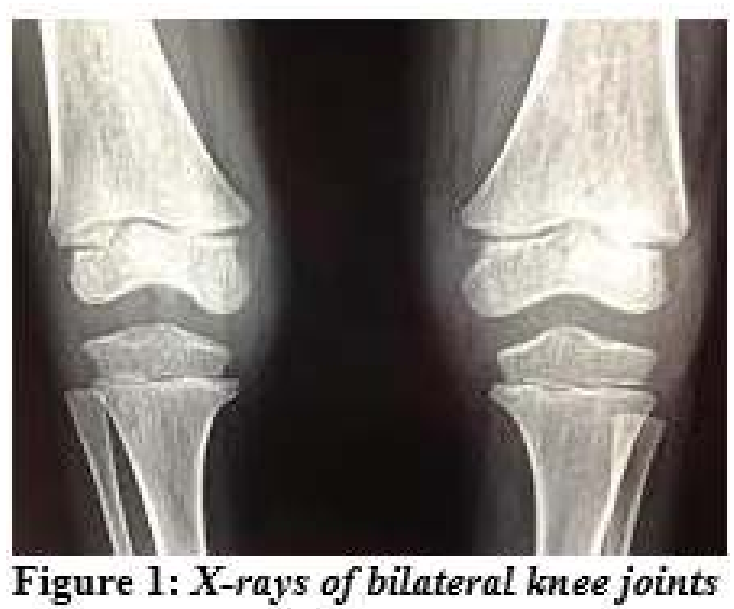

Echocardiogram revealed a structurally and functionally normal heart. Magnetic resonance imaging (MRI) of the brain revealed marginal communicating hydrocephalus, cerebral atrophy and delayed myelination. 


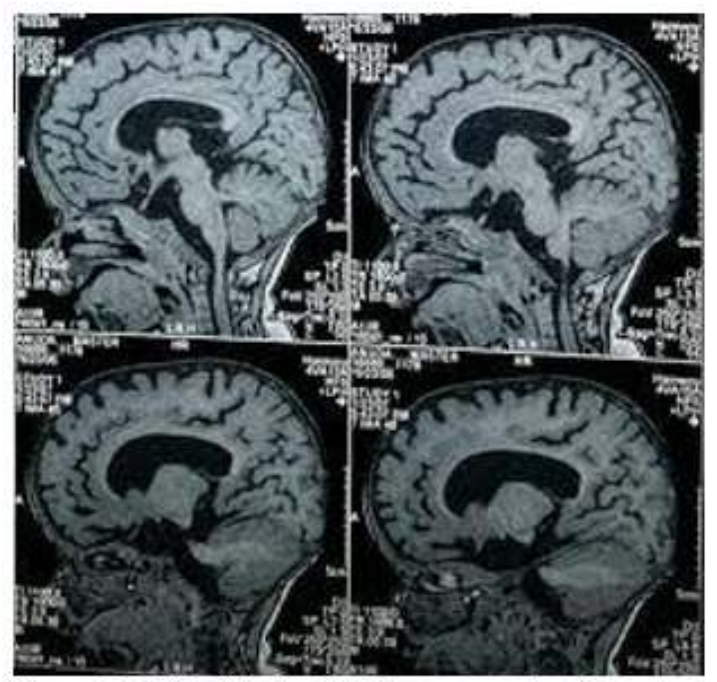

Figure 2: MRI of brain showing communicating hydrocephalus, cerebral atrophy \& delayed myelination

\section{Discussion}

NOMID was first described by Prieur and Griscelli ${ }^{2}$. Symptoms commence at birth or early infancy ${ }^{3}$. The disease characteristically begins with a maculopapular rash with urticarial features ${ }^{4}$ and studies have shown that this rash appears in $100 \%$ of children with NOMID. Our patient had recurrent urticaria since 4 months of age. Failure to thrive, hepatomegaly, intermittent fever, anaemia, leucocytosis, generalized lymphadenopathy and painful arthropathy manifest with evolution of the disease $^{5}$. Our patient had all these findings except painful arthropathy. Morphologic features include short stature, macrocephaly, and clubbing of fingers and the child reported here had all those clinical features $^{6}$. The skeletal manifestations in this child included osteoporosis and delayed bone age, which are well described in NOMID syndrome ${ }^{7}$. Ocular manifestations in our patient included papilloedema and optic atrophy which are reported manifestations of NOMID syndrome. Hydrocephalus, cerebral atrophy and intellectual impairment are well described central nervous system features ${ }^{7}$ and all were observed in the currently reported child. Reported laboratory abnormalities include neutrophil leucocytosis, persistent hypochromic microcytic anaemia, and elevated erythrocyte sedimentation rate ${ }^{7}$ and all these laboratory features were present in our patient.

NOMID syndrome occurs following a mutation in NLRP3 gene which helps control inflammation. However, the inheritance may be heterogeneous and only up to $60 \%$ will have demonstrable mutation in the aforementioned gene ${ }^{8}$. Mutations in the same gene are also found in Muckle-Wells syndrome and familial cold-induced auto-inflammatory syndrome ${ }^{9}$, but these 2 conditions can be differentiated by the clinical profile. NOMID runs a chronic relapsing course without definitive cure.
Treatment of NOMID syndrome is challenging and interleukin 1 (IL1) receptor antagonist, Anakinra, helps mitigate systemic inflammation in $\mathrm{NOMID}^{10}$. The outcome is better if it is commenced before the development of arthropathy ${ }^{8}$. Non-steroidal antiinflammatory drugs (NSAIDS) and steroids relieve pain, fever and joint mobility temporarily as reported previously ${ }^{11}$. Azathioprine, colchicine, cyclosporin, etanercept, infliximab, intravenous immunoglobulin, methotrexate, penicillamine, salazopyrin and thalidomide have been tried in reported cases with no consistent response ${ }^{11}$.

\section{References}

1. Prieur AM. A recently recognized chronic inflammatory disease of early onset characterized by the triad of rash, central nervous system involvement and arthropathy. Clinical and Experimental Rheumatology 2001; 19: 103-6.

PMid: 11247311

2. Prieur AM, Griscelli C, Lampert F, Truckenbrodt H, Guggenheim MA, Lovell DJ, et al. A chronic, infantile, neurological, cutaneous and articular (CINCA) syndrome. A specific entity analysed in 30 patients. Scandinavian Journal of Rheumatology Supplement 1987; 66:57-68. https://doi.org/10.3109/030097487091025 23

PMid: 3482735

3. Dollfus H, Hafner R, Hofmann HM, Prieur AM. Chronic infantile neurological cutaneous and articular/neonatal onset multisystem inflammatory disease syndrome: Ocular manifestations in a recently recognized chronic inflammatory disease of childhood. Archives of Ophthalmology 2000; 118(10):1386-92. https://doi.org/10.1001/archopht.118.10.1 386

PMid: 11030821

4. Kaufman RA, Lovell DJ. Infantile-onset multisystem inflammatory disease: Radiologic findings. Radiology 1986; 160:741-6.

https://doi.org/10.1148/radiology.160.3.37 37913

PMid: 3737913

5. Prieur AM, Griscelli C. Arthropathy with rash, chronic meningitis, eye lesions, and mental retardation. Journal of Pediatrics 1981; 99(1):79-83. https://doi.org/10.1016/S00223476(81)80 961-4 
6. Hashkes PJ, Lovell DJ. Recognition of infantile-onset multisystem inflammatory disease as a unique entity. Journal of Pediatrics 1997; 130: 513-5.

PMid: 9108844

7. Hill SC, Namde M, Dwyer A, Poznanski A, Canna S, Goldbach-Mansky R. Arthropathy of neonatal onset multisystem inflammatory disease (NOMID/CINCA). Pediatric Radiology 2007; 37(2):145-52. https://doi.org/10.1007/s00247-006-03580

PMid: 17136361

8. Miyamae $\mathrm{T}$, Inaba $\mathrm{Y}$, Nishimura $\mathrm{G}$, Kikuchi M, Kishi T, Hara R, et al. Effect of anakinra on arthropathy in CINCA/NOMID syndrome. Pediatric Rheumatology 2010 March 16; 8:9. Available from: http://link.springer.com/article/10.1186/15 46-0096-8-9
9. Dode C, Le Du N, Cuisset L, Letourneur F, Berthelot JM, Vaudor G. New mutations of CIAS1 that are responsible for MuckleWells syndrome and familial cold urticaria: a novel mutation underlies both syndromes. American Journal of Human Genetics 2002; 70:1498-506. https://doi.org/10.1086/340786 PMid: 11992256 PMCid: PMC379138

10. Kilcline C, Shinkai K, Bree A, Modica R, Von Scheven E, Frieden IJ. Neonatal-onset multisystem inflammatory disorder: the emerging role of pyrin genes in autoinflammatory diseases. Archives of Dermatology 2005; 141(2):248-53. https://doi.org/10.1001/archderm.141.2.24 8

PMid: 15724022

11. Khemani C, Khubchandani R. CINCA syndrome. Indian Pediatrics 2007; 44:9336.

PMid: 18175851 